\title{
The Efficacy of Nasal Surgery on Pharyngeal Airway
}

\author{
Sung Ho Yoon ${ }^{1},{\text { Hyung Chae } \text { Yang }^{1} \text { (D), Nutsalai Galiulina }}^{2}$, Tae Gu Kang ${ }^{1}$, \\ Hee Young Kim ${ }^{1}$, Hye Rin Lim¹, and Sang Chul Lim ${ }^{1}$ \\ ${ }^{I}$ Department of Otolaryngology-Head and Neck Surgery, Chonnam National University Medical School, Chonnam National University \\ Hospital, Gwangju, Korea; and ${ }^{2}$ National Hospital of the Kyrgyz Republic, Bishkek, Kyrgyzstan
}

\section{비강수술이 인두기도에 미치는 영향 분석}

윤성호 ${ }^{1}$ 양형채 ${ }^{1} \cdot$ Nutsalai Galiulina $^{2} \cdot$ 강태구 $^{1} \cdot$ 김희영 $^{1} \cdot$ 임혜린 $^{1} \cdot$ 임상철 $^{1}$

전남대학교 의과대학 전남대학교병원 이비인후과학교실, ${ }^{1}$ 키르키즈공화국 국립병원 이비인후과 ${ }^{2}$

\author{
Received February 17, 2019 \\ Revised May 28, 2019 \\ Accepted July 17, 2019 \\ Address for correspondence \\ Hyung Chae Yang, MD, PhD \\ Department of Otolaryngology- \\ Head and Neck Surgery, \\ Chonnam National University \\ Medical School, Chonnam \\ National University Hospital, \\ 42 Jebong-ro Dong-gu, \\ Gwangju 61469, Korea \\ Tel $+82-62-220-6776$ \\ Fax $+82-62-228-7743$ \\ E-mail blessed@jnu.ac.kr
}

Background and Objectives Nasal surgery is known to improve the quality of life in patients with obstructive sleep apnea; however, its effect on the airway structure is little known. This study attempted to identify the impact of nasal surgery on the pharyngeal airway structure. Subjects and Method We enrolled in the study patients who underwent nasal surgery from July 2015 to March 2018 due to nasal obstruction with severe snoring or sleep apnea. Patients with palate surgery or previous history of airway surgery were excluded. Demographic factors, symptoms regarding nasal obstruction, sleep study, preoperative cephalometry, and postoperative 3-month cephalometry were taken into account and analyzed. We also performed a subgroup analysis according to the severity of sleep apnea.

Results Sixty-three patients were enrolled in this study. Soft palate thickness showed no significant change. Pre and postoperative soft palate thickness were $10.82 \pm 3.00$ and $11.11 \pm 3.35$ $(p=0.261)$, respectively. However, the pharyngeal airway space was enlarged via nasal surgery from $12.05 \pm 3.35$ to $13.04 \pm 3.35$ ( $p=0.006$ ), respectively. The subgroup analysis showed that the pharyngeal airway was mainly enlarged in the patients with lower Apnea-Hypopnea Index (AHI). Conclusion Although nasal surgery does not reduce soft palate thickness, it can enlarge the pharyngeal airway space. The effect of surgery would be more prominent in patients with AHI of lower than 15 event/hour $(p=0.005)$ as nasal surgery alone does not affect the pharyngeal airway of patients with AHI greater than 15 .

Korean J Otorhinolaryngol-Head Neck Surg 2020;63(1):21-5

Key Words Cephalometry $\cdot$ Nasal surgery $\cdot$ Obstructive sleep apnea $\cdot$ Pharynx $\cdot$ Snoring.

\section{서 론}

수면무호흡증은 중추성 수면무호흡과 폐쇄성 수면무호흡, 수면관련 저환기/저산소 증후군으로 구분될 수 있으며, 이 중 65세 이하 성인의 상당수는 폐쇄성 수면무호흡이라고 알려져 있다. 폐쇄성 수면무호흡증은 호흡운동을 하려는 노력이 있 으나 상기도의 폐쇄로 인하여 기류순환이 막히면서 발생하며,

This is an Open Access article distributed under the terms of the Creative Common Attribution Non-Commercial License (https://creativecommons.org/licenses/by-nc/4.0) which permits unrestricted non-commercial use, distribution, and reproduction in any medium, provided the original work is properly cited.
비강, 구강, 비인두, 구인두, 하인두, 후두 등이 원인이 된다. ${ }^{2)}$

비강의 기류순환은 만성 비후성 비염, 비용, 비중격 만곡 등에 영향받을 수 있으며, 적절한 비호흡이 불가능해지면, 구강호흡이 야기되기도 한다. 비폐색으로 인해 야기되는 구 강 호흡은 연구개를 포함한 구인두 부위의 떨림(fluttering) 을 일으키고, 또한 설기도의 후방 이동을 야기하여 2차적인 설기저부의 폐색을 야기함으로 수면무호흡을 더욱 악화시 키는 것으로 생각된다. 따라서 이들 환자들에서 비중격 성 형술 등 비강 수술을 시행하는 경우 환자의 삶의 질을 향상 시키고 ${ }^{3-5)}$ 양압기 사용자에서는 사용압력을 낮춰준다고 알 
려져 있다. ${ }^{6}$

하지만 비중격수술이 무호흡-저호흡지수(Apnea-Hypopnea Index, AHI)를 낮추는지 여부에 대해서는 논란이 있으며, ${ }^{7,8)}$ 또한 이들 수술이 기도에 미치는 직접적인 영향은 연구되지 않았다. 이에 본 연구자는 코골이나 수면무호흡을 주소로 내원한 환자들 중 코막힘을 호소하는 환자를 대상으 로 비중격 성형술을 시행하고, 비중격 성형술이 인두 기도의 크기 및 연구개 두께에 미치는 영향을 확인해 보고자 하였다.

\section{대상 및 방법}

2015년 7월에서 2018년 3월 사이 코골이 또는 수면무호흡 을 주소로 내원한 환자들 중 코막힘을 동반하여 비중격 교 정술이나 비 성형술을 포함한 비강 수술을 시행한 환자들을 그 대상으로 하였다. 구개 수술이나, 이전 안면부 수술 과거 력이 있는 환자 및 18 세 이하의 소아는 연구에서 제외하였 다. 환자들의 인구학적 특성과, 이학적 검사상의 특성 및 수 면다원검사상의 지표들이 평가되었으며, 술 전과 술 후 두부 $\mathrm{X}$-선 규격사진 계측 결과를 비교하였으며, 또한, 비중격 수 술의 효과가 수면무호흡의 중증도에 따라 차이가 있는지 확 인하기 위해 AHI 15 를 기준으로 경증 수면무호흡군(AHI $<15)$ 과 중등-고도 수면무호흡군 $(\mathrm{AHI} \geq 15)$ 으로 군을 구분 하여 비교분석하였다. 본 연구는 본원의 기관생명윤리위원회 심의를 통과하였다(CNUH-2019-044).

비강 수술의 기본이 되는 비중격 성형술은 앙와위 자세에 서 시행되었으며, 국소마취 혹은 전신마취하에 시행되었다. 1:100000으로 희석된 epinephrine 용액을 포함하는 $1 \%$ lidocaine을 수술 부위 점막연골막하에 침윤마취한 후, 넓은 쪽 비강으로 접근하여 변형된 Killian 절개, 혹은 반관통절 개를 시행하였다. Cottle 거상기를 이용하여 점막연골막을 비중격연골에서 분리하며, 연골과 상악릉을 분리하고, 만곡 을 야기하는 잉여연골이나 비중격릉, 또는 극 등을 교정한 후, 비중격관통봉합을 시행하여 수술을 마무리하였다. 이외 비밸부 부위의 패색이나, 상부 혹은 비부 비중격변형이 심한 환자에서는 외비 성형술을 시행하였으며, 하비갑개의 비대 가 저명한 환자에서는 하비갑개 수술을 동시에 시행하였다.

수술 전, 후로 두부 $\mathrm{X}$-선 규격사진 계측을 시행하였고 두 부 X-선 규격사진 계측을 통해 술 전 및 술 후 연구개의 두 께 및 인두 기도의 크기를 측정하였다. 두부 $\mathrm{X}$-선 규격사진 촬영은 본과와 관련이 없는 동일한 영상시설에서 동일한 자 세를 요구하며 촬영하였다. 연구개의 두께는 연구개 음영이 보이는 곳에서 가장 두꺼운 부분을 측정하였으며, 인두 기도 의 크기는 $\mathrm{Cl}$ 척추뼈의 앞결절에서 인두 기도의 음영에 직각

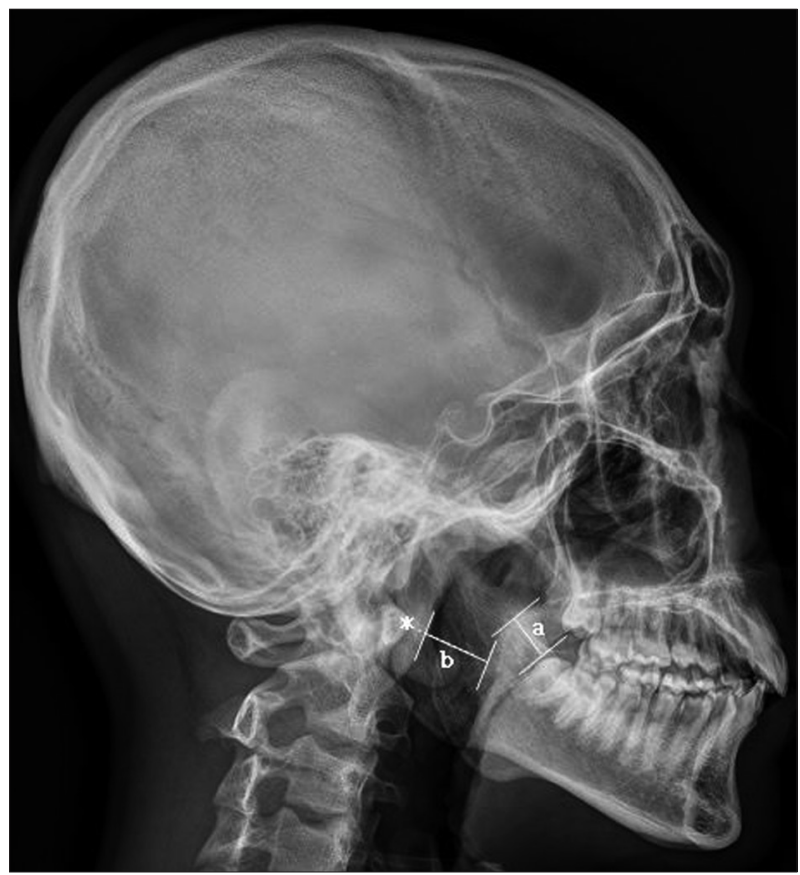

Fig. 1. Cephalometric measurement of retropalatal posterior airway space (asterick: C1 vertebra anterior tubercle, a: soft palate thickness, b: retropalatal posterior airway space).

으로 선을 그어 만나는 부위에서 측정하였다(Fig. 1). 분석은 마로뷰 분석 소프트웨어를 사용하였으며(Maroview, version 5.4, Marotech, Seoul, Korea), 계측에 계측자의 주관적인 판 단이 영향을 미치지 않게 하기 위해 수술이나 해당 환자의 진료와는 관련이 없는 이비인후과 의사 한 명이 모든 계측을 시행하였다.

연구에 참여한 환자들은 수술 전에 수면다원검사를 받았 다. 수면다원검사는 Embla N7000과 RemLogic 2.0.0(Embla Systems, Denver, CO, USA) 프로그램을 이용하여 시행 하였으며, 시행 결과는 American Academy of Sleep Medicine guideline에 따라 판독되었다. ${ }^{9)}$ 각각의 검사는 산소포 화도 측정을 위한 pulse oximetry, 심전도(electrocardiography), 뇌전도(electroencephalography), 양측 안전도(electrooculography), 턱밑혀근(genioglossus)과 전경골근(tibialis anterior)에 대한 근전도, 무호흡 및 저호흡 측정을 위한 external thermistor와 nasal pressure transducer, 호흡노력 측정을 위한 dual thoracoabdominal respiratory inductance plethysmography 벨트, 코골이 측정을 위한 마이크로 폰 및 환자의 수면자세를 파악하기 위한 piezo-electrical 센 서 등을 포함하였다.

통계는 SPSS 23(IBM Corp., Armonk, NY, USA)을 사용 하였다. 환자의 나이, AHI, 체질량지수와 같은 연속변수들은 평균과 표준편차를 기록하였으며, 성별, 기저질환과 같은 범 주형 변수들은 백분율로 표시되었다. 통계적 유의성 검증을 
위해 범주형 변수는 Fisher's exact tests를 시행하였으며, 연 속변수는 Mann-Whitney U test를 시행하였다.

\section{결 과}

총 63명의 환자를 대상으로 분석이 진행되었다. 여성은 13 명, 남성은 50 명이었으며, 기저질환으로 고혈압이 있는 사람 이 7 명, 당뇨가 있는 사람이 2 명이었다. 환자들의 평균 연령 은 41.10 \pm 15.93 세였다.

63명 전체 환자의 술 전 측정한 연구개 두께 및 술 후 측 정한 연구개 두께의 평균은 각각 $10.82 \pm 3.00 \mathrm{~mm}$ 와 $11.11 \pm$ $3.35 \mathrm{~mm}$ 로 통계학적 차이는 보이지 않았으나 $(p=0.261)$, 술 전 측정한 인두기도 크기 및 술 후 측정한 인두 기도 크기의 평균은 $12.05 \pm 3.35 \mathrm{~mm}$ 에서 $13.04 \pm 3.35 \mathrm{~mm}$ 로 인두 기도 의 크기가 통계학적으로 유의미하게 증가하였다 $(p=0.006)$ (Table 1).

또한 본 연구에서는 비강수술의 효과가 수면무호흡의 중 증도에 따라 차이가 있는지 확인하기 위해 AHI 15 를 기준으 로 군을 나누어 분석하였다(Table 2). 연구개의 두께는 경증
수면무호흡군 및 중등-고도 수면무호흡군 양 군 모두에서 술 전과 술 후의 차이가 없었다. 인두 기도의 크기는 경증 수 면무호흡군에서는 술 전 $12.51 \pm 3.12 \mathrm{~mm}$ 에서 술 후 $13.67 \pm$ $3.15 \mathrm{~mm}$ 로 유의미하게 증가하였으나 $(p=0.005)$, 중등-고도 수면무호흡군에서는 술 전, 술 후 각각 $11.01 \pm 3.69 \mathrm{~mm}$ 에서 $11.57 \pm 3.42 \mathrm{~mm}$ 로 변화되는 것으로 나타나 통계학적으로 유 의미한 차이는 $(p=0.416)$ 보이지 않았다(Table 3).

\section{고 찰}

최근 삶의 질 향상과 국내 의료환경의 변화로 수면다원검 사를 시행하는 환자가 급격히 증가하였다. 검사를 통해 폐쇄 성 수면무호흡으로 진단되는 환자에게는 양압기, 구강장치, 상기도근 강화훈련 등의 비수술적 치료를 우선 고려해 볼 수 있고, 비수술적 치료의 실패 시 수술적 치료를 시행해 볼 수 있다. 이때 가장 먼저 고려되는 수술 중 한 가지가 비폐색을 해결해주기 위한 수술이다.

비폐색은 비강기도를 통해 이뤼지는 양압치료를 직접적으 로 방해할 수 있으며, 또한 비폐색으로 인해 발생하는 구강

Table 1. Soft palate thickness and retropalatal posterior airway space of study population before and after nasal surgery $(n=63)$

\begin{tabular}{lccc}
\hline & Pre-op & Post-op & p-value* \\
\hline Soft palate thickness $(\mathrm{mm})$ & $10.82 \pm 3.00$ & $11.11 \pm 3.35$ & 0.261 \\
Retropalatal posterior airway space $(\mathrm{mm})$ & $12.05 \pm 3.35$ & $13.04 \pm 3.35$ & 0.006 \\
\hline
\end{tabular}

Variables are presented as means \pm standard deviation. *the Mann-Whitney $U$ test was used to analyze soft palate thickness and posterior airway space at soft palate. Pre-op: pre-operative measurement, Post-op: post-operative measurement

Table 2. Clinical characteristics of study population according to the severity of obstructive sleep apnea

\begin{tabular}{|c|c|c|c|c|}
\hline & Total & $\mathrm{AHI}<15$ & $\mathrm{AHI} \geq 15$ & p-value* \\
\hline Number & 63 & 44 & 19 & \\
\hline Age & $41.10 \pm 15.93$ & $37.36 \pm 16.24$ & $51.58 \pm 9.68$ & 0.000 \\
\hline Sex (male/female) & $50 / 13$ & $35 / 9$ & $15 / 4$ & 0.958 \\
\hline \multicolumn{5}{|l|}{ Underlying diseases } \\
\hline $\mathrm{DM}$ & 2 & $0(0)$ & $2(10.5)$ & 0.542 \\
\hline HTN & 7 & $1(2.3)$ & $6(31.6)$ & 0.005 \\
\hline AHI (/hour) & $12.96 \pm 2.02$ & $2.07 \pm 3.64$ & $38.17 \pm 20.20$ & 0.000 \\
\hline F/U duration (months) & $7.24 \pm 5.79$ & $7.86 \pm 6.00$ & $5.79 \pm 5.13$ & 0.194 \\
\hline \multicolumn{5}{|l|}{ NOSE } \\
\hline Pre-operative measurement & $10.21 \pm 5.34$ & $11.02 \pm 4.95$ & $8.37 \pm 5.85$ & 0.071 \\
\hline Post-operative measurement & $3.79 \pm 3.72$ & $3.76 \pm 3.81$ & $3.88 \pm 3.58$ & 0.915 \\
\hline \multicolumn{5}{|l|}{ SNOT-25 } \\
\hline Pre-operative measurement & $47.65 \pm 28.25$ & $51.49 \pm 28.31$ & $38.95 \pm 26.82$ & 0.108 \\
\hline Post-operative measurement & $23.33 \pm 18.15$ & $22.95 \pm 18.87$ & $24.24 \pm 16.83$ & 0.809 \\
\hline
\end{tabular}

Continuous variables are presented as means \pm standard deviation and categorical variables are presented as number (percentage). *the Mann-Whitney U test was used to analyze age, AHI, F/U duration, NOSE, SNOT-25. The $\chi^{2}$ test and Fisher's exact test were used to analyze the sex, and underlying diseases. AHI: Apnea-Hypoapnea Index, HTN: hypertension, DM: diabetes mellitus, NOSE: nasal obstruction and septoplasty effectiveness scale, SNOT-25: sinonasal outcome, Pre-op: pre-operative measurement, Post-op: post-operative measurement 
Table 3. Soft palate thickness and retropalatal posterior airway space of study population to the severity of obstructive sleep apnea

\begin{tabular}{|c|c|c|c|}
\hline & Pre-op & Post-op & p-value* \\
\hline \multicolumn{4}{|c|}{ Soft palate thickness (mm) } \\
\hline $\mathrm{AHI}<15(\mathrm{n}=44)$ & $10.58 \pm 3.27$ & $10.93 \pm 3.80$ & 0.223 \\
\hline $\mathrm{AHI} \geq 15(\mathrm{n}=19)$ & $11.38 \pm 2.24$ & $11.52 \pm 1.98$ & 0.794 \\
\hline \multicolumn{4}{|c|}{ Retropalatal posterior airway space (mm) } \\
\hline $\mathrm{AHI}<15(\mathrm{n}=44)$ & $12.51 \pm 3.12$ & $13.67 \pm 3.15$ & 0.005 \\
\hline $\mathrm{AHI} \geq 15(\mathrm{n}=19)$ & $11.01 \pm 3.69$ & $11.57 \pm 3.42$ & 0.416 \\
\hline
\end{tabular}

Continuous variables are presented as means \pm standard deviation. *the Mann-Whitney $U$ test was used to analyze soft palate thickness and posterior airway space at soft palate. AHI: Apnea-Hypoapnea Index, Pre-op: pre-operative measurement, Post-op: post-operative measurement

호흡에 의한 설기저부의 후방 이동으로 2 차적인 기도폐색을 야기할 수 있다. 비강기도 폐색을 해결하기 위해 비중격 성형 술이나 하비갑개 점막하 절제술 등을 시행하지만, 이들 수술 이 수면무호흡증의 가장 중요한 지표 중 하나인 AHI에 미치 는 영향은 논란이 많다. ${ }^{10,11)}$ 하지만, 비강수술이 양압기 사용 압력을 낮춰주는 효과가 있고, ${ }^{12-14)}$ 이와 함께 양압기 사용 순응도를 높여주는 것은 잘 알려져 있다. ${ }^{6,15-18)}$

본 연구는 비강수술이 인두부위 상부 기도에 미치는 효과 를 확인하고자 하였다. 이를 위해 인두 부위 기도 크기의 변 화를 판단할 수 있는 두부 X-선 규격사진 계측상의 두 가지 지표인 연구개 두께와 기도 넓이를 평가하였다. 이 두 가지 지표는 기존 연구들에서도 수면무호흡 환자에서 두부 X-선 규격사진 계측을 통해 평가할 수 있는 지표로 알려져 있으 며, 수면무호흡이 심한 환자에서 연구개의 두께는 두껍고 기 도크기는 작은 것으로 나타나 있다. ${ }^{19)}$ 또한 다양한 원인에 의 해 야기되는 수면무호흡의 특성을 고려하여, 상대적으로 비 중격만곡이 다른 원인에 비해 큰 영향을 미칠 것으로 예상되 는 경도의 수면무호흡 환자군에서 비강에 대한 수술이 더 저 명한 효과를 보일 수 있을 것이라 판단하였다. 따라서, 본 연 구에서는 비강 수술을 시행한 수면무호흡 환자를 대상으로, 중증도를 기준으로 그룹을 나누어 두부 $\mathrm{X}$-선 규격사진 계 측을 진행하였다.

분석 결과는 비강 수술이 비강과 연결된 구인두 부위의 기 도 크기를 확장시키는 것을 보여준다. 비강 수술에 따른 기 도 크기 변화는 경도의 수면무호흡 환자에서 변화가 큰 것으 로 나타났다. 이는 비강폐색이 중등-고도 수면무호흡 환자보 다 경도의 환자의 병인에 상대적으로 큰 영향을 미쳤기 때문 으로 판단된다. 중등-고도 수면무호흡 환자에서는 비강 수술 로 인한 기도 크기 변화는 없었다. 이는 중등도 이상의 수면 무호흡 환자의 경우 비폐색뿐만 아니라 높은 체질량지수, 측 부인두의 해부학적 비대 등 다양한 다른 원인들이 비폐색보 다 더 큰 영향을 미치기 때문인 것으로 사료된다.

구인두 직경은 $12.51 \mathrm{~mm}$ 에서 $13.67 \mathrm{~mm}$ 로 $1 \mathrm{~mm}$ 정도의
증가만 보여 실제 기도의 크기가 크게 증가한 것은 아니다. 하지만, 이 결과는 총 62 명이라는 많지 않는 환자수를 대상 으로 분석에서도 통계적 유의성 $(p=0.005)$ 을 보이는 결과이 며, 또한 구인부의 지름은 비록 $1 \mathrm{~mm}(8.2 \%)$ 증가에 불과하 지만, 그것이 호흡량(volumetric flow)에 미치는 영향은 공기 의 밀도와 속도가 같다고 가정했을 때, ${ }^{20)}$ 단면적인 제곱에 비 례하게 되므로 $17 \%$ 정도 늘어날 수 있다고 생각된다. 이와 함 께, 이 결과는 수술이나 기타 시술에 의한 직접적인 영향이 아닌, 비강 수술로 인한 구인두의 2차적인 구조 변화로 사료 되므로 단순한 $1 \mathrm{~mm}$ 증가 이상의 의미가 있다고 생각된다.

구인두 부위의 기도 크기가 연구개의 두께 감소에 의한 것 인지 확인하기 위해 연구개 두께에 대한 측정도 시행되었다. 하지만 연구개 두께는 환자의 중증 여부에 무관하게 비강 수 술에 영향을 받지 않았다. 통계적 유의성은 없지만 일부 군 에서는 오히려 두께가 증가한 것으로 보인다. 이런 점들을 고 려해 볼 때, 기도가 확장된 것은 연구개 두께가 줄어든 것 때 문은 아닌 것으로 판단된다.

이것보다는, 비강 구조가 개선되면서 비호흡의 양이 많아 진 것이 원인일 것으로 사료된다. 즉, 유량은 공기의 밀도, 단 면적, 속도에 비례하는데, ${ }^{21)}$ 비강 구조의 호전에 의해 비강으 로 유입되는 공기의 양이 증가하게 되면, 다른 변수들이 고정 되었다고 가정할 때, 유량의 증가는 단면적의 증가를 야기할 것으로 사료된다. 또한, 수술 전에는 증가된 비강저항으로 인 해 구인두 부위의 내부 압력이 낮아져 구인두가 허탈되었으 나, 비강 수술에 의해 비강구조가 개선되면서, 비강 저항이 감소되고, 이에 따라 이와 연결된 구인두 부위의 내부 압력이 높아져 허탈이 해결되면서 인두 기도가 확장되었을 가능성이 있다. ${ }^{22,23)}$ 이 외에도 구강 호흡이 비호흡으로 바뀐 것이 원인 일 수 있다. 구호흡에 의해 야기되던 인두 부위의 염증이 줄 어들고, 이로 인해 기도의 상태가 호전되면서, 다른 논문들에 서 보고되는 삶의 질 향상을 야기하는 것으로 생각된다. ${ }^{424,25)}$

본 연구는 인두 기도의 크기와 연구개의 두께를 두부 $\mathrm{X}^{-}$ 선 규격사진 계측을 통해 측정하였으나 두부 X-선 규격사진 
계측 시 목의 신전 및 구부림 정도가 인두 기도의 크기나 연 구개의 두께에 영향을 미칠 수 있다는 점에서 변수가 있을 수 있겠다. 하지만, 모든 환자가 동일한 영상시설에서 동일한 자세를 요구받으며 촬영되었으며, 같은 환자에서 술 전 및 술 후를 측정하였으므로, 측정 시 오류에 의한 영향은 적을 것 으로 판단된다. 또한 전체 연구 대상자의 수가 충분하지 않 은 점도 있었으며, 추후 좀 더 많은 수의 환자들을 대상으로 하는 추가적인 연구가 필요하겠다.

본 연구는 비폐색 해결을 위한 비강 수술이 구인두 부위의 인두 기도를 확장시켜주는 것을 확인하였다. 기도 확장 효과 는 중등도 이상의 수면무호흡 환자보다는 경도의 수면무호흡 이나 단순 코골이 환자에서 더 저명하며, 이는 경도의 수면무 호흡 환자에서 비폐색이 병인에 미치는 영향이 크기 때문인 것으로 사료된다. 이런 점을 고려할 때 경도의 수면무호흡 환 자에서는 비강 수술을 우선적으로 고려해 볼 수 있을 것이다.

\section{Acknowledgments}

This research was supported by Basic Science Research Program through the National Research Foundation of Korea (NRF) funded by the Ministry of Education (NRF-2018R1D1A1B07046906) and a grant (BCRI-18020) of Chonnam National University Hospital Biomedical Research Institute.

\section{Author Contribution}

Conceptualization: Hyung Chae Yang, Sang Chul Lim. Data curation: Nutsalai Galiulina, Tae Gu Kang, Hee Young Kim, Hye Rin Lim. Formal analysis: Nutsalai Galiulina, Tae Gu Kang, Hee Young Kim, Hye Rin Lim. Funding acquisition: Hyung Chae Yang. Investigation: Sung Ho Yoon. Methodology: Hyung Chae Yang, Sang Chul Lim. Project administration: Sung Ho Yoon. Resources: Hyung Chae Yang, Sang Chul Lim. Software: Sung Ho Yoon. Supervision: Sang Chul Lim. Validation: Tae Gu Kang. Visualization: Nutsalai Galiulina. Writing - original draft: Sung Ho Yoon. Writing - review \& editing: Nutsalai Galiulina, Tae Gu Kang, Hee Young Kim, Hye Rin Lim.

\section{ORCID}

Hyung Chae Yang https://orcid.org/0000-0002-9187-1367

\section{REFERENCES}

1) Young T, Peppard PE, Gottlieb DJ. Epidemiology of obstructive sleep apnea: a population health perspective. Am J Respir Crit Care Med 2002;165(9):1217-39.

2) Park WS, Ji YB, Lee SH, Jeong JH, Song CM, Tae K. Long-term effects of adenotonsillectomy on growth and symptoms in childhood. Korean J Otorhinolaryngol-Head Neck Surg 2018;61(12):681-5.

3) Kim DW, Kim NK, Kim WH, Lee JS, Choi DJ. Effect of nasal surgery in patients with remained snoring and sleep apnea after obstructive sleep apnea surgery. Korean J Otorhinolaryngol-Head Neck Surg 2016;59(8):588-92.

4) Li HY, Lin Y, Chen NH, Lee LA, Fang TJ, Wang PC. Improvement in quality of life after nasal surgery alone for patients with obstructive sleep apnea and nasal obstruction. Arch Otolaryngol Head Neck Surg 2008;134(4):429-33.

5) Jang HU, Jung SS, Nam YM, Kim JS. The effect of septoturbinoplasty for quality of life in patients with sleep-disordered breathing. Korean J Otorhinolaryngol-Head Neck Surg 2011;54(4):257-64.

6) Camacho M, Riaz M, Capasso R, Ruoff CM, Guilleminault C, Kushida CA, et al. The effect of nasal surgery on continuous positive airway pressure device use and therapeutic treatment pressures: A systematic review and meta-analysis. Sleep 2015;38(2):279-86.

7) Kim ST, Choi JH, Jeon HG, Cha HE, Kim DY, Chung YS. Polysomnographic effects of nasal surgery for snoring and obstructive sleep apnea. Acta Otolaryngol 2004;124(3):297-300.

8) Koutsourelakis I, Georgoulopoulos G, Perraki E, Vagiakis E, Roussos C, Zakynthinos SG. Randomised trial of nasal surgery for fixed nasal obstruction in obstructive sleep apnoea. Eur Respir J 2008;31(1):110-7.

9) Berry RB, Brooks R, Gamaldo C, Harding SM, Lloyd RM, Quan SF, et al. AASM scoring manual updates for 2017 (version 2.4). J Clin Sleep Med 2017;13(5):665-6.

10) Wu J, Zhao G, Li Y, Zang H, Wang T, Wang D, et al. Apneahypopnea index decreased significantly after nasal surgery for obstructive sleep apnea: A meta-analysis. Medicine (Baltimore) 2017;96(5):e6008.

11) Roh HJ, Koo HE, Jeong HS, Koo SK, Lee SH. The Effect of Nasal Obstruction on Sleep Apnea. Korean J Otorhinolaryngol-Head Neck Surg 2000;43(6):626-30.

12) Nakata $S$, Noda A, Yagi $H$, Yanagi E, Mimura $T$, Okada $T$, et al. Nasal resistance for determinant factor of nasal surgery in CPAP failure patients with obstructive sleep apnea syndrome. Rhinology 2005;43(4):296-9.

13) Nowak C, Bourgin P, Portier F, Genty E, Escourrou P, Bobin S. [Nasal obstruction and compliance to nasal positive airway pressure]. Ann Otolaryngol Chir Cervicofac 2003;120(3):161-6.

14) Friedman M, Tanyeri H, Lim JW, Landsberg R, Vaidyanathan K, Caldarelli D. Effect of improved nasal breathing on obstructive sleep apnea. Otolaryngol Head Neck Surg 2000;122(1):71-4.

15) Esteller E, Matiñó E, Segarra F, Sanz JJ, Ademà JM, Estivill E. [Adverse effects of continuous positive airway pressure therapy and its relation to the nose]. Acta Otorrinolaringol Esp 2004;55(1): $17-22$

16) Hollandt $\mathrm{JH}$, Mahlerwein M. Nasal breathing and continuous positive airway pressure (CPAP) in patients with obstructive sleep apnea (OSA). Sleep Breath 2003;7(2):87-94.

17) Ripberger R, Pirsig W. [Nasal positive pressure ventilation (nCPAP) in therapy of obstructive sleep apnea: acceptance by 50 patients]. Laryngorhinootologie 1994;73(11):581-5.

18) Sériès F, St Pierre S, Carrier G. Effects of surgical correction of nasal obstruction in the treatment of obstructive sleep apnea. Am Rev Respir Dis 1992;146(5 Pt 1):1261-5.

19) Kurt G, Sisman C, Akin E, Akcam T. Cephalometric comparison of pharyngeal airway in snoring and non-snoring patients. Eur $\mathrm{J}$ Dent 2011;5(1):84-8.

20) Embree PM, O'Brien WR. Volumetric blood flow via time-domain correlation: Experimental verification. IEEE Trans Ultrason Ferroelectr Freq Control 1990;37(3):176-89.

21) Miller RW. Flow measurement engineering handbook. 1st ed. New York, NY: McGraw Hill;1983.

22) Park CS. The role of nose in sleep and sleep disorder. Korean $J$ Otorhinolaryngol-Head Neck Surg 2012;55(4):201-5.

23) Gold AR, Schwartz AR. The pharyngeal critical pressure. The whys and hows of using nasal continuous positive airway pressure diagnostically. Chest 1996;110(4):1077-88.

24) Löth S, Petruson B, Wirén L, Wilhelmsen L. Better quality of life when nasal breathing of snoring men is improved at night. Arch Otolaryngol Head Neck Surg 1999;125(1):64-7.

25) Miyazaki S, Itasaka Y, Ishikawa K, Togawa K. Influence of nasal obstruction on obstructive sleep apnea. Acta Otolaryngol Suppl 1998;537:43-6. 